Research Paper

\title{
Extract of Cornus officinalis Protects Keratinocytes from Particulate Matter-induced Oxidative Stress
}

\author{
Pincha Devage Sameera Madushan Fernando1, Mei Jing Piao1, Ao Xuan Zhen¹, Mee Jung Ahn², Joo Mi Yi³, \\ Yung Hyun Choi ${ }^{4}$, Jin Won Hyun ${ }^{1 凶}$ \\ 1. Department of Biochemistry, College of Medicine, Jeju National University, Jeju 63243, Republic of Korea. \\ 2. Laboratory of Veterinary Anatomy, College of Veterinary Medicine, Jeju National University, Jeju 63243, Republic of Korea. \\ 3. Department of Microbiology and Immunology, College of Medicine, Inje University, Busan 47392, Republic of Korea. \\ 4. Department of Biochemistry, College of Oriental Medicine, Dongeui University, Busan 47340, Republic of Korea. \\ $\triangle$ Corresponding author: Jin Won Hyun, Department of Biochemistry, College of Medicine, Jeju National University, Jeju 63243, Republic of Korea. Telephone: \\ +82-64-754-3838; Fax: +82-64-754-3838; E-mail: jinwonh@jejunu.ac.kr. \\ (0) The author(s). This is an open access article distributed under the terms of the Creative Commons Attribution License (https://creativecommons.org/licenses/by/4.0/). \\ See http://ivyspring.com/terms for full terms and conditions.
}

Received: 2019.05.08; Accepted: 2019.11.08; Published: 2020.01.01

\begin{abstract}
The skin is one of the large organs in the human body and the most exposed to outdoor contaminants such as particulate matter $<2.5 \mu \mathrm{m}\left(\mathrm{PM}_{2.5}\right)$. Recently, we reported that $\mathrm{PM}_{2.5}$ induced cellular macromolecule disruption of lipids, proteins, and DNA, via reactive oxygen species, eventually causing cellular apoptosis of human keratinocytes. In this study, the ethanol extract of Cornus officinalis fruit (EECF) showed anti-oxidant effect against PM2.5-induced cellular oxidative stress. EECF protected cells against PM 2.5 -induced DNA damage, lipid peroxidation, and protein carbonylation. $\mathrm{PM}_{2.5}$ up-regulated intracellular and mitochondrial $\mathrm{Ca}^{2+}$ levels excessively, which led to mitochondrial depolarization and cellular apoptosis. However, EECF suppressed the $\mathrm{PM}_{2.5}$-induced excessive $\mathrm{Ca}^{2+}$ accumulation and inhibited apoptosis. The data confirmed that EECF greatly protected human $\mathrm{HaCaT}$ keratinocytes from PM2.5-induced oxidative stress.
\end{abstract}

Key words: ethanol extract of Cornus officinalis fruits (EECF); particulate matter $2.5\left(\mathrm{PM}_{2.5}\right)$; human HaCaT keratinocytes; oxidative stress

\section{Introduction}

Particulate matter (PM) is an air pollutant with harmful effects on the human skin that contribute to conditions such as skin cancers, alopecia, and skin aging $[1,2]$. In particular, the harmful effects of PM depend on the composition of deleterious contents such as heavy metals $(\mathrm{Cu}, \mathrm{Mn}, \mathrm{Ni}, \mathrm{Pb}$, and $\mathrm{Ti})$ and polycyclic aromatic hydrocarbons [3]. PM $<2.5 \mu \mathrm{m}$ $\left(\mathrm{PM}_{2.5}\right)$ is considered fine $\mathrm{PM}$ and its detrimental effects on the human skin are mediated by the generation of excessive intracellular reactive oxygen species (ROS), which creates oxidative stress [4-6]. $\mathrm{PM}_{2.5}$-mediated excessive ROS generation could elicit lipid peroxidation, DNA damage, apoptotic protein expression, and mitochondria-dependent apoptosis, which eventually results in skin irritation and damage [7].

There are more than 65 species classified under the genus Cornus (family Cornaceae), but only two species, Cornus mas and Cornus officinalis, have been reported as medicinal plants used in traditional medicine [8]. These plants are mainly distributed in eastern Asia including Korea, Japan, and China. C. officinalis is commonly known as cornel dogwood or Asiatic dogwood [9]. C. officinalis grows up to 4-10 m high, has papery leaves that are 5.5-10 cm long, its flowers consist of four petals with a yellow lanceolate tongue that is $3.3 \mathrm{~mm}$ long [10]. C. officinalis fruit has been used to treat high blood pressure, kidney deficiency, dizziness, spermatorrhea, and waist and knee pain since ancient times [10,11]. Most related pharmacological studies have revealed that the ethanol extract of $C$. officinalis fruit (EECF) possesses anti-hyperglycemia, anti-aging, immune-regulatory, and renal and neuro-protective effects [12]. In addition, the neuro-protective, antioxidant, antiinflammatory, cardiovascular, and anti-diabetic effects of the EECF have been revealed [13]. Furthermore, C. officinalis fruit contain high amounts 
of volatile compounds, organic acids, carbohydrates, tannins, and iridoids. Particularly, iridoid glycosides are one of the active ingredients in the $C$. officinalis fruit [14]. However, there are few reports of the cytoprotective effect of EECF against $\mathrm{PM}_{2.5}$-induced oxidative stress in human keratinocytes. Therefore, this study was conducted to investigate the potential of EECF to cure the $\mathrm{PM}_{2.5}$-induced cell damage.

\section{Materials and methods}

\section{Reagents and chemicals}

The dried fruit of C. officinalis collected from an area around the city of Gurye (Jeollanam-do Province, Republic of Korea), were provided by Gurye Sansuyu Farming Association Corporation. For the preparation of EECF, the dried fruit $(20 \mathrm{~g})$ were cut into small pieces and extracted three times with $400 \mathrm{~mL} \mathrm{70 \%}$ ethanol at $4^{\circ} \mathrm{C}$ for $3 \mathrm{~h}$. After filtering, the filtrate was concentrated using a vacuum rotary evaporator (EYELA SB-1000, Tokyo Rikakikai Co. Ltd., Tokyo, Japan). The residue was then freeze-dried using a freeze dryer and stored at $-80^{\circ} \mathrm{C}$. The powder (EECF) was dissolved in dimethyl sulfoxide (DMSO, Sigma-Aldrich Chemical Co., St. Louis, MO, USA) to obtain a final concentration of $100 \mathrm{mg} / \mathrm{mL}$ (extract stock solution), and was stored at $4^{\circ} \mathrm{C}$. The stock solution was diluted with culture medium to the desired concentrations prior to use. EECF was dissolved in DMSO. Diesel $\mathrm{PM}_{2.5}$ (NIST SRM 1650b, $\mathrm{PM}_{2.5}$ ) was purchased from Sigma-Aldrich Chemical Co. and was dissolved in DMSO to prepare the stock solution $(25 \mathrm{mg} / \mathrm{mL})$. To avoid agglomeration of the suspended $\mathrm{PM}_{2.5}$, the solution was sonicated for 30 $\min [15]$.

\section{Cell culture}

The human HaCaT keratinocytes (Cell Line Service, Heidelberg, Germany) were cultured in Dulbecco's modified Eagle's medium (DMEM, Life Technologies Corporation, Staley Rd, Grand Island, USA). The medium was supplemented with antibiotic solution consisting of 100 units $/ \mathrm{mL}$ penicillin, 100 $\mu \mathrm{g} / \mathrm{mL}$ streptomycin, and $0.25 \mu \mathrm{g} / \mathrm{mL}$ amphotericin $\mathrm{B}$ (Gibco, Life Technologies Co., Grand Island, NY, USA). In addition, the medium was supplemented with $10 \%$ fetal bovine serum. The cultured cells were incubated in a $100 \%$ humidified atmosphere at $37^{\circ} \mathrm{C}$ with $5 \% \mathrm{CO}_{2}$.

\section{Cell viability}

The cytotoxicity of the EECF on HaCaT cells was measured using the 3-(4,5-dimethylthiazol-2-yl)-2,5diphenyl tetrazolium bromide (MTT) assay. Cells were cultured in a 96-well plate at a density of $1.0 \times$ $10^{5}$ cells per well and specific wells were separately treated with EECF at final concentrations of 25, 50, $100,200,300,400$, and $500 \mu \mathrm{g} / \mathrm{mL}$. The MTT stock solution $(2 \mathrm{mg} / \mathrm{mL})$ was incubated with the cells for 4 $\mathrm{h}$ until formazan crystals were formed. The crystals were then dissolved in DMSO and the absorbance of the reaction solution was detected using a multi-well spectrophotometer at a wavelength of $540 \mathrm{~nm}$.

\section{DPPH radical detection}

$\operatorname{EECF}(25,50,100,200,300,400$, and $500 \mu \mathrm{g} / \mathrm{mL})$ was mixed with $0.15 \mathrm{mM}$ 2,2-diphenyl-1picrylhydrazyl (DPPH), shaken gently, and kept in the dark for $3 \mathrm{~h}$. The residual DPPH was determined at $520 \mathrm{~nm}$ using a spectrophotometer.

\section{ROS detection}

Cells were seeded in 96 well palate at a $1.5 \times 10^{5}$ cell density and intracellular ROS levels those generated via $1 \mathrm{mM}$ hydrogen peroxide $\left(\mathrm{H}_{2} \mathrm{O}_{2}\right)$, were measured using the $2^{\prime}, 7^{\prime}$-dichlorofluorescein diacetate (DCF-DA, Sigma-Aldrich) assay. Cells were seeded on chamber slides at a $1.5 \times 10^{5}$ cell density and incubated with $\mathrm{PM}_{2.5}(50 \mu \mathrm{g} / \mathrm{mL})$ for $1 \mathrm{~h}$. The cells were stained with DCF-DA for $30 \mathrm{~min}$ and the fluorescence emission was detected using confocal microscopy (Carl Zeiss, Oberkochen, Germany).

\section{Detection of superoxide anion}

Superoxide anion was generated though the reaction between 5,5-dimethylpyrroline-N-oxide (DMPO) and the xanthine/xanthine oxidase system. The generated $\mathrm{DMPO} / \mathrm{OOH}$ adduct was detected using electron spin resonance (ESR). Then, $20 \mu \mathrm{L}$ xanthine oxidase $(0.25 \mathrm{U} / \mathrm{mL})$ was mixed with $20 \mu \mathrm{L}$ each of xanthine $(10 \mathrm{mM}), \mathrm{EECF}(200 \mu \mathrm{g} / \mathrm{mL})$, and 3 $\mathrm{M}$ DMPO, and after $2.5 \mathrm{~min}$, the ESR signaling was measured. ESR spectrophotometer settings were set as follows: power, $1.00 \mathrm{~mW}$; central magnetic field, $336.8 \mathrm{mT}$; frequency, $9.4380 \mathrm{GHz}$; amplitude, 600; modulation width, $0.2 \mathrm{mT}$; sweep width, $10 \mathrm{mT}$; sweep time, $30 \mathrm{sec}$; gain, 500; time constant, $0.03 \mathrm{sec}$; temperature, $25^{\circ} \mathrm{C}$ [16].

\section{Lipid peroxidation assay}

A four-well chamber slide was used to plate the cells in the presence of $200 \mu \mathrm{g} / \mathrm{mL}$ EECF, followed by exposure to $\mathrm{PM}_{2.5}(50 \mu \mathrm{g} / \mathrm{mL})$ for $24 \mathrm{~h}$ and staining with diphenyl-1-pyrenylphosphine (DPPP) for $30 \mathrm{~min}$ in the dark. Images were analyzed using a confocal microscope [15].

\section{Protein carbonylation assay}

Cells were incubated with $200 \mu \mathrm{g} / \mathrm{mL}$ EECF for 1 $\mathrm{h}$ and treated with $\mathrm{PM}_{2.5}(50 \mu \mathrm{g} / \mathrm{mL})$ for $24 \mathrm{~h}$. Protein oxidation was assessed using an OxiSelect ${ }^{\mathrm{TM}}$ protein carbonyl enzyme-linked immunosorbent assay kit 
(Cell Biolabs, San Diego, CA, USA) according to the manufacturer's instructions.

\section{Single-cell gel electrophoresis}

Cells were seeded in the medium with 200 $\mu \mathrm{g} / \mathrm{mL}$ EECF in a $1 \mathrm{~mL}$ micro tube for $30 \mathrm{~min}$ and treated with $\mathrm{PM}_{2.5}(50 \mu \mathrm{g} / \mathrm{mL})$ for another $30 \mathrm{~min}$. After coating with $110 \mu \mathrm{L} 0.7 \%$ low-melting agarose, the cells were immersed in lysis buffer $(2.5 \mathrm{M} \mathrm{NaCl}$, $100 \mathrm{mM} \mathrm{Na} \mathrm{Na}_{2}$ EDTA, $10 \mathrm{mM}$ Tris, 1\% N-lauroylsarcossinate) for $1 \mathrm{~h}$ at $4^{\circ} \mathrm{C}$. An electrical field (300 $\mathrm{mA}, 25 \mathrm{~V}$ ) was used for electrophoresis. Slides were stained with $40 \mu \mathrm{L}$ ethidium bromide $(10 \mu \mathrm{g} / \mathrm{mL})$ and analyzed using the comet 5.5 image analyzer (Andor Technology, Belfast, UK). The percentage total fluorescence and tail lengths were recorded (50 cells per slide).

\section{Detection of 8-oxoguanine (8-oxoG) expression}

ROS-induced DNA damage was assessed using the avidin-tetramethylrhodamine isothiocyanate (TRITC, 1:200) conjugate (Sigma-Aldrich) assay, based on fluorescence-binding activity. Initially, the cells were fixed on chamber slides at a $1.5 \times 10^{5}$ cell density and images of fluorescence-visualized cells were captured using a confocal microscope [17].

\section{Detection of $\mathrm{Ca}^{2+}$ level}

Treated cells were loaded with $10 \mu \mathrm{M}$ fluoro-4-acetoxymethyl ester (Fluo-4-AM) or rhod-2acetoxymethyl ester (Rhod-2-AM, Molecular Probes) for $30 \mathrm{~min}$ to detect intracellular $\mathrm{Ca}^{2+}$ level and mitochondrial $\mathrm{Ca}^{2+}$, respectively. Fluorescence was measured using confocal microscopy [18].

\section{Mitochondrial membrane potential $\left(\Delta \Psi_{\mathrm{m}}\right)$ analysis}

Cells were seeded on chamber slides at a density of $1.5 \times 10^{5}$ cells. After treatment with EECF (200 $\mu \mathrm{g} / \mathrm{mL})$, cells were exposed to $\mathrm{PM}_{2.5}(50 \mu \mathrm{g} / \mathrm{mL})$ for $24 \mathrm{~h}$, stained with $5 \mu \mathrm{M} 5,5^{\prime}, 6,6^{\prime}$-tetrachloro-1,1',3,3'tetraethylbenzimidazolylcarbocyanine iodide (JC-1, Invitrogen, Carlsbad, CA, USA), and analyzed using confocal microscopy.

\section{Western blotting}

Harvested cells were lysed using $150 \mu \mathrm{L}$ of protein lysis buffer and the collected cell lysates were centrifuged at 13,000 $\mathrm{rpm}$ for $5 \mathrm{~min}$. The resulting suspensions were collected and protein levels were analyzed as previously described [19]. Aliquots were electrophoresed using $12 \%$ sodium dodecyl sulfatepolyacrylamide gel electrophoresis. Then, the separated proteins were transferred onto the nitrocellulose membranes, which were sequentially incubated with the appropriate primary and secondary antibodies. Protein bands were detected using the Amersham ECL western blotting detection reagents and analysis system (GE healthcare, Amersham place, UK).

\section{Hoechst 33342 staining}

Cells were treated with $200 \mu \mathrm{g} / \mathrm{mL}$ EECF for $1 \mathrm{~h}$, followed by $\mathrm{PM}_{2.5}(50 \mu \mathrm{g} / \mathrm{mL})$ for $18 \mathrm{~h}$. The cells were stained with Hoechst $33342(20 \mu \mathrm{M})$ and DNA-specific fluorescence was visualized using a fluorescence microscope. Nuclear condensation levels were evaluated and quantified for the apoptotic cells.

\section{Statistical analysis}

All experiments were performed in triplicate. Data are presented as the means \pm standard error and were analyzed using the Sigma Stat 3.5 version software (Systat Software Inc., San Jose, CA, USA) using Tukey's test and analysis of variance (ANOVA). A $P<0.05$ was considered statistically significant.

\section{Results}

\section{EECF reduced ROS generation}

Before commencing the experiment, we sought to determine if EECF had any cytotoxicity on human $\mathrm{HaCaT}$ keratinocytes using the MTT assay with different EECF concentrations (0, 25, 50, 100, 200, 300, 400, and $500 \mu \mathrm{g} / \mathrm{mL}$, Figure 1A). The results confirmed that EECF was not cytotoxic against $\mathrm{HaCaT}$ cells at any of the tested concentrations. EECF showed DPPH radical scavenging activity at all the tested concentrations compared with $\mathrm{N}$-acetylcysteine (NAC), a well-known antioxidant (Figure 1B). Next, the ROS scavenging ability of EECF was tested, and concentrations of $25-200 \mu \mathrm{g} / \mathrm{mL}$ showed rapidly increasing ROS (generated via $1 \mathrm{mM} \quad \mathrm{H}_{2} \mathrm{O}_{2}$, respectively) scavenging activity and, therefore, 200 $\mu \mathrm{g} / \mathrm{mL}$ was selected as the optimal concentration for further experiments (Figure 1C). To assess the ability of EECF $(200 \mu \mathrm{g} / \mathrm{mL})$ to scavenge superoxide anion, ESR spectrometry was performed. Superoxide anions produced by the xanthine/xanthine oxidase system were reduced by EECF, as shown in Figure 1D. The generated signal of 2,996 in the control was reduced to 1,505 in the presence of EECF. Intracellular ROS generation assessed using the DCF-DA assay revealed that $200 \mu \mathrm{g} / \mathrm{mL}$ EECF ameliorated the green color intensity caused by the $\mathrm{PM}_{2.5}$, which was visualized using confocal microscopy (Figure 1E).

\section{EECF significantly attenuated $\mathrm{PM}_{2.5}$-induced lipid peroxidation, protein carbonylation, and DNA damage}

The lipid peroxidation amount was assessed by 
visualizing the fluorescent intensity of oxidized DPPP, which is an indicator of lipid peroxidation. The DPPP oxidase intensity was higher in $\mathrm{PM}_{2.5}$-treated cells than it was in control cells. Pretreatment with EECF significantly reduced the florescent intensity of $\mathrm{PM}_{2.5}$-containing cells (Figure 2A). The results indicated that EECF treatment has the potential to reduce ROS generation and further confirmed the ROS scavenging properties. Then, protein carbonylation was measured. Carbonyl groups are formed during the process of protein oxidation [16]. $\mathrm{PM}_{2.5}$ significantly increased the expression of carbonyl moieties, whereas EECF-pretreated cells exhibited notably reduced formation of protein

A

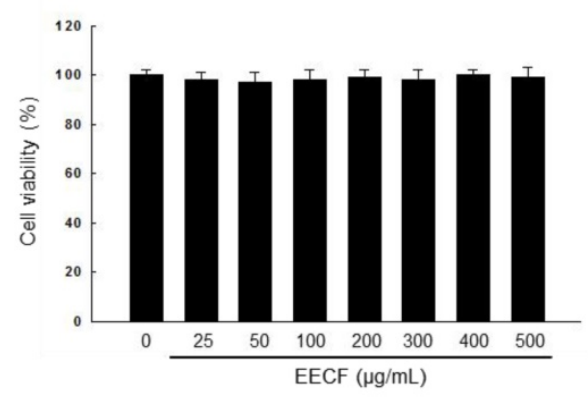

C

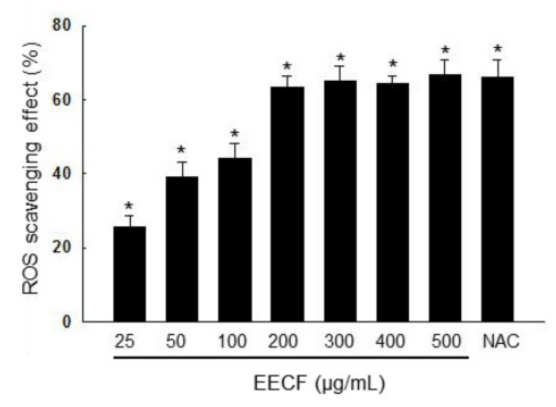

E

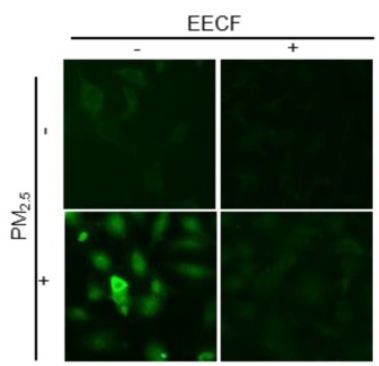

carbonyl when they were exposed to $\mathrm{PM}_{2.5}$ (Figure 2B). Furthermore, $\mathrm{PM}_{2.5}$-induced DNA damage was monitored using a comet assay. As shown in Figure $2 \mathrm{C}$, treatment with the $\mathrm{PM}_{2.5}$ distinctly elongated the comet tail and increased the damaged DNA around the nuclei. Pre-treatment of HaCaT cells with EECF before exposure to $\mathrm{PM}_{2.5}$ obviously reduced the level of damaged DNA in comet tails. Finally, the level of 8 -oxoG was analyzed using confocal microscopy, and $\mathrm{PM}_{2.5}$-treated cells showed the highest 8-oxoG level. $\mathrm{PM}_{2.5}$ exposure caused severe DNA lesions in cells, which were revealed by avidin-TRITC binding. Furthermore, EECF was shown to attenuate the $\mathrm{PM}_{2.5}$-induced DNA lesions (Figure 2D).

\section{B}

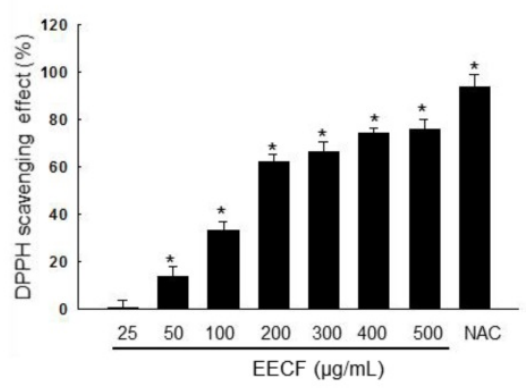

D
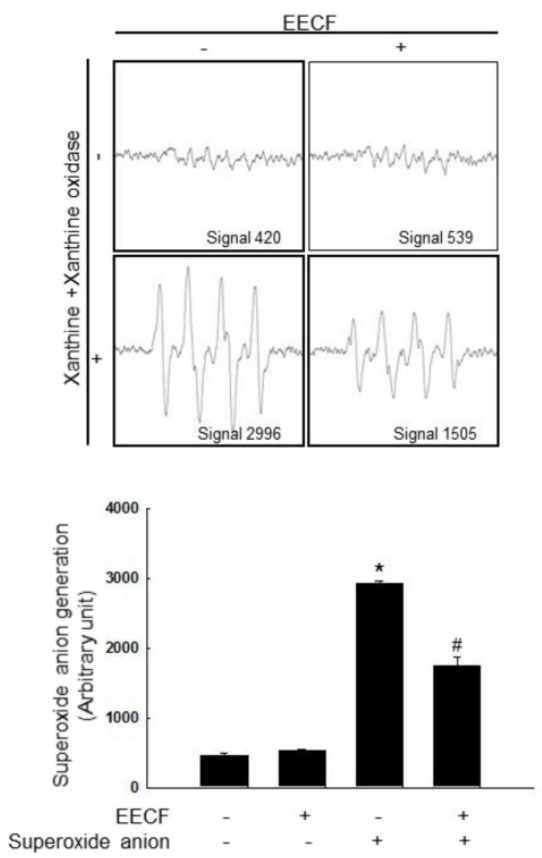

Figure 1. Ethanol extract of $C$. officinalis fruit (EECF) reduced ROS generation. (A) MTT assay was used to assess cell viability of EECF ( $0,25,50,100,200,300,400$, and $500 \mu \mathrm{g} / \mathrm{mL}$ )-treated $\mathrm{HaCaT}$ cells for $24 \mathrm{~h}$. (B) Radical-scavenging effects of EECF were investigated using DPPH assay. ${ }^{*} \mathrm{P}<0.05$ compared with control. (C) Intracellular ROS level that generated by $\mathrm{H}_{2} \mathrm{O}_{2}(1 \mathrm{mM})$, was detected using spectrophotometer after DCF-DA staining. NAC is the positive control. * $p<0.05$ compared with control. (D) Superoxide anion reducing ability of $200 \mu \mathrm{g} / \mathrm{mL} E E C F$ was investigated using xanthine/xanthine oxidase system. ${ }^{*} p<0.05$ and $\# p<0.05$, compared with control and superoxide anion-treated group, respectively. (E) Effect of EECF on PM 2.5 -induced intracellular ROS generation was assessed using DCF-DA staining by confocal microscopy. 
A

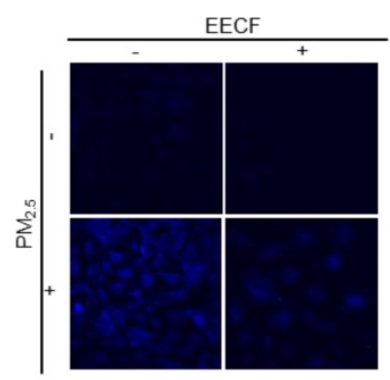

C
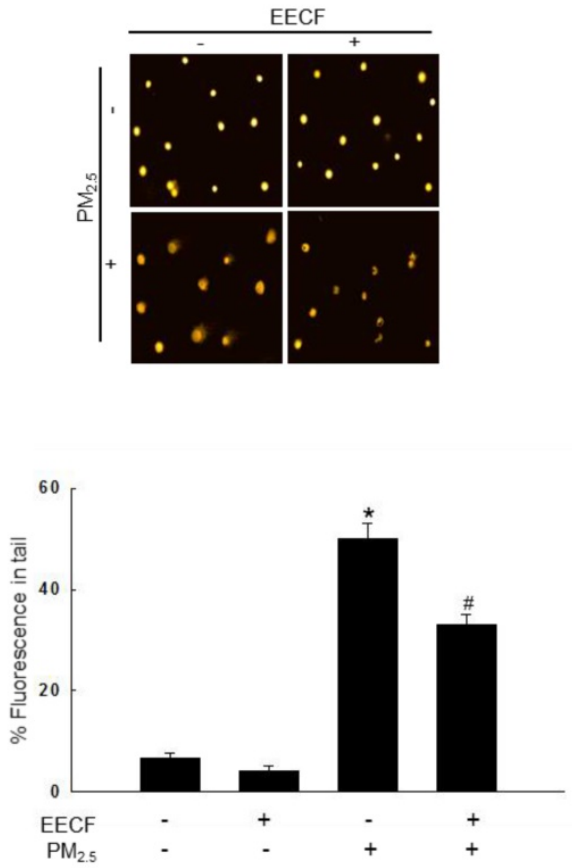

B

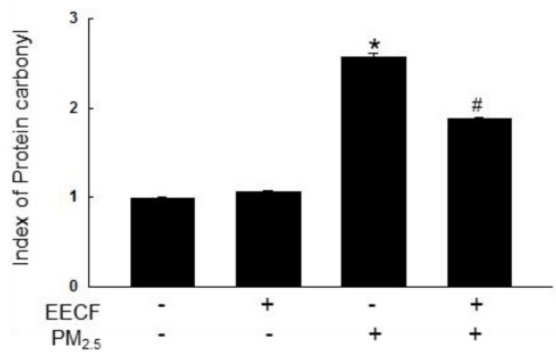

D

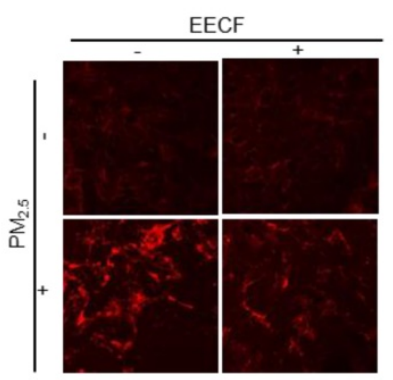

Figure 2. Ethanol extract of $C$. officinalis fruit (EECF) protected cells against PM2.5-induced lipid peroxidation, protein carbonylation, and DNA damage. (A) EECF effect on $\mathrm{PM}_{2.5}$-induced lipid peroxidation was assessed using confocal microscopy after DPPP staining. (B) Protein oxidation was assessed by measuring carbonyl formation. ${ }^{*} p<0.05$ and ${ }^{\#} p<0.05$, compared to control and $\mathrm{PM}_{2.5}$-treated group, respectively. (C) DNA damage was assessed using comet assay. ${ }^{*} p<0.05$ and ${ }^{\#} p<$ 0.05 , compared to control and PM2.5-treated group, respectively. (D) Avidin-TRITC conjugate was examined to evaluate DNA oxidative adducts of 8-oxoG using confocal microscopy.

\section{EECF attenuated $\mathbf{P M}_{2.5}$-induced mitochondrial stress}

Initially, we hypothesized that the oxidative ability of $\mathrm{PM}_{2.5}$ was mediated by mitochondrial stress. Therefore, intracellular $\mathrm{Ca}^{2+}$ level were assessed, because previous studies have reported that disruption of $\mathrm{Ca}^{2+}$ homeostasis generates mitochondrial stress [15]. Cells were stained with Fluo-4-AM dye, and confocal microscopy analysis revealed that $\mathrm{Ca}^{2+}$ fluorescence was much higher in the $\mathrm{PM}_{2.5}$-treated group than in the other cells. Pretreatment with EECF obviously reduced the intracellular $\mathrm{Ca}^{2+}$ level of $\mathrm{PM}_{2.5}$-treated cells (Figure $3 \mathrm{~A})$. The mitochondrial $\mathrm{Ca}^{2+}$ level was assessed by staining cells with Rhod-2-AM dye and the confocal microscopy analysis revealed that treatment with EECF notably reduced the level(Figure 3B). The $\Delta \psi_{\mathrm{m}}$ was assessed using JC-1 dye, where red and green fluorescence indicated the polarized and depolarized state of the mitochondria, respectively [20]. The results indicated that mitochondrial depolarization was enhanced by $\mathrm{PM}_{2.5}$ but was notably reduced by EECF, as shown in the confocal microscopy analysis (Figure 3C). 
A

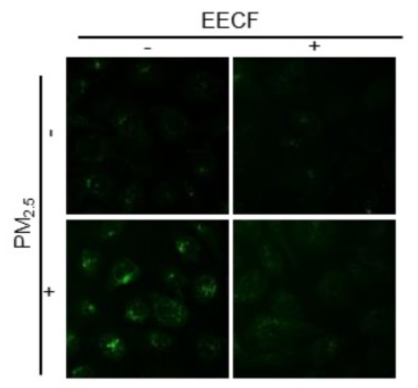

B

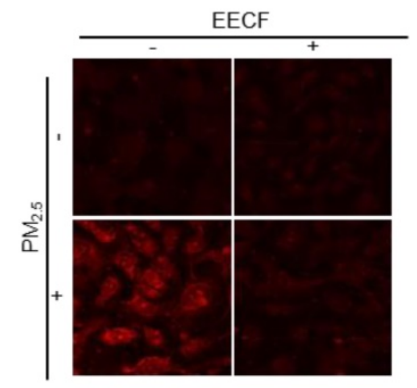

C

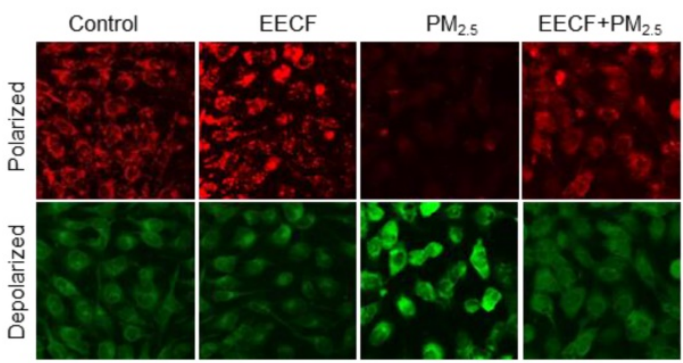

Figure 3. Ethanol extract of $C$. officinalis fruit (EECF) attenuated $\mathrm{PM}_{2.5}$-induced mitochondrial stress. (A) Effect of EECF on intracellular $\mathrm{Ca}^{2+}$ was assessed using confocal microscopy after Fluo-4-AM staining. (B) EECF effect on the mitochondrial $\mathrm{Ca}^{2+}$ level was assessed using confocal microscopy after Rhod-2-AM staining. (C) Mitochondrial membrane potential $\left(\Delta \psi_{\mathrm{m}}\right)$ was detected using JC-1 staining.

A

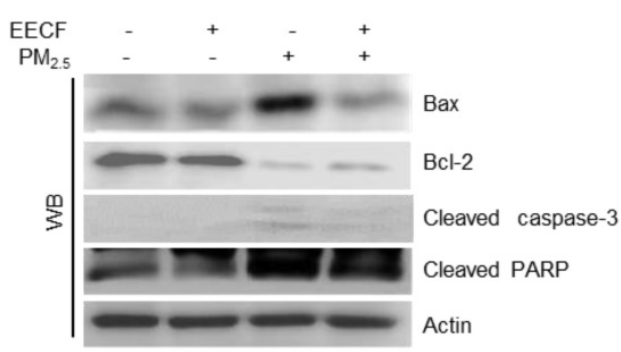

B

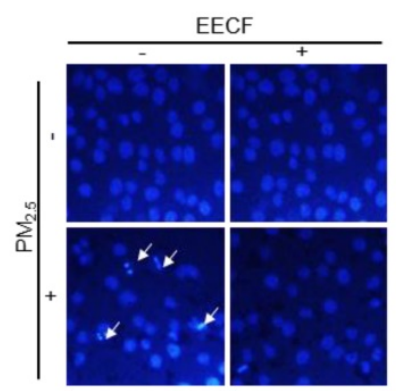

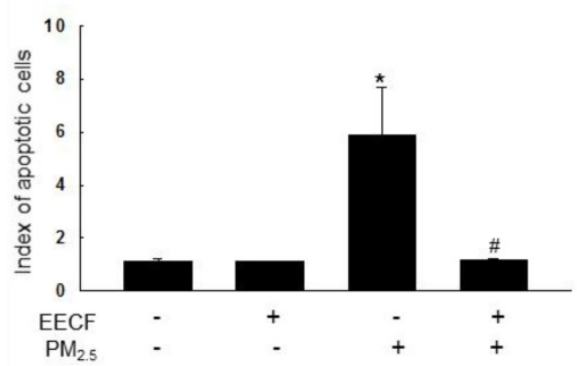

Figure 4. Ethanol extract of $C$. officinalis fruit (EECF) attenuated the PM 2.5 -induced cellular apoptosis. (A) Cell lysates were analyzed for Bax, Bcl-2, cleaved caspase-3, and cleaved PARP protein expression using western blot (WB). (B) Cells were stained with Hoechst 33342 dye and apoptotic cells were observed and quantified. The arrow indicates apoptotic cells. ${ }^{*} p<0.05$ and ${ }^{*} p<0.05$, compared to control and $\mathrm{PM}_{2.5}$-treated group, respectively.

\section{PM 2.5 -induced cell apoptosis was attenuated by EECF}

$\mathrm{PM}_{2.5}$ enhanced the expression of cleaved caspase-3, cleaved poly-ADP ribose polymerase
(PARP) and B-cell lymphoma-2-associated X protein (Bax) and decreased the expression of B-cell lymphoma-2 (Bcl-2) (Figure 4A). This finding suggests that caspase-3 was likely involved in the observed cell apoptosis. However, pretreatment with EECF 
attenuated the cell apoptosis, and the cell nuclei stained with Hoechst 33342 were analyzed using microscopy, which showed significant nuclear condensation in $\mathrm{PM}_{2.5}$-treated cells. Cells pretreated with EECF were observed to be normal (Figure 4B).

\section{Discussion}

The skin is the largest organ in the body and it protects the body by acting as a barrier to the external environment [21-23]. $\mathrm{PM}_{2.5}$ is considered an air pollutant, which has harmful effects on the skin, such as skin aging and inflammatory skin diseases, mediated by the generation of intracellular ROS $[24,25]$. One of the most recent studies has reported that dried sarcocarp of $C$. officinalis consists of 11 highly polar compounds, particularly, iridoid isomers (7a-O-methylmorroniside, 7 3 -O-methylmorroniside,

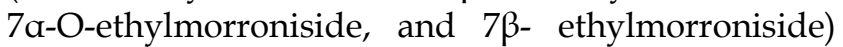
[26]. Gallic acid, 5-hydroxymethylfurfural, morroniside, and loganin are the most abundant compounds in the C. officinalis fruit; however, their content could vary with the state of the fruit, depending on whether they are processed or crude. Particularly, loganin possesses immune-regulatory and anti-inflammatory activities, while morroniside is involved in the prevention of diabetic angiopathy [27]. In the present study, EECF did not show cytotoxicity at any of the tested concentrations as reported previously [28]. A previous study reported that EECF has relatively high DPPH radical scavenging activity, mediated by its antioxidant activity [29]. In agreement with previously reported findings, the results of this study indicate that EECF scavenged DPPH radical and superoxide anion (Figures 1B and 1D). It has been reported that EECF contains flavonoids, which are known to possess antioxidant activity via hydrogen donation [28,30]. Our results showed that EECF exhibited antioxidant activity by attenuating hydrogen peroxide-induced ROS generation, and ameliorated intracellular ROS generation, as revealed by DCF-DA staining (Figures $1 \mathrm{C}$ and $1 \mathrm{E}$ ).

$\mathrm{PM}_{2.5}$-induced ROS caused oxidative damage, which resulted in protein carbonylation, lipid peroxidation, and DNA damage [31]. ROS attack proteins by oxidation, which is the main mechanism of protein modification. Furthermore, protein modification can be reversible or irreversible. Protein modification leads to protein carbonylation, protein-protein cross linking, and adduct formation with lipid peroxidation products. Eventually, proteins become fragmented and degraded by ROS-mediated protein modification [32]. ROS affect lipids, mainly through hydroxyl radical and hydroperoxyl. Especially, polyunsaturated fatty acids are converted to lipid peroxyl radical and hydroperoxide as the result of oxygen insertion. Eventually, lipid peroxidation negatively affects cellular functions such as protein synthesis and alters biochemical properties [33]. It has been reported that $\mathrm{PM}_{2.5}$ can arrest the cell cycle, resulting in DNA damage and the level of 8-OHdG (an oxidative DNA adduct) [34]. DPPP staining revealed that, EECF has an ability to reduce the $\mathrm{PM}_{2.5}$-induced lipid peroxidation (Figure 2A). In addition, our results illustrated that EECF pretreatment significantly attenuated protein carbonyl formation in cells while the comet assay revealed the protective effect of EECF on $\mathrm{PM}_{2.5^{-}}$ induced DNA damage. EECF significantly attenuated the DNA strand breaking and at $200 \mu \mathrm{g} / \mathrm{mL}$, also reduced the elevated 8-oxoG level in $\mathrm{PM}_{2.5}$-treated cells.

A previous study reported that cellular oxidative stress causes mitochondria stress, which eventually results in cell apoptosis [35]. Oxidative stress could be further enhanced by mitochondrial $\mathrm{Ca}^{2+}$ accumulation, while the endoplasmic reticulum releases $\mathrm{Ca}^{2+}$. As previously reported, ROS degrade the $\Delta \psi_{\mathrm{m}}$ [36], and our results revealed that EECF strongly ameliorated $\mathrm{PM}_{2.5}$-induced excessive $\mathrm{Ca}^{2+}$ accumulation in the cell and mitochondria. This effect restored cellular $\mathrm{Ca}^{2+}$ homeostasis and EECF restored the $\Delta \psi_{\mathrm{m}}$. In conclusion, our results confirmed that EECF has considerable antioxidant activity against $\mathrm{PM}_{2.5^{-}}$ induced skin damage.

\section{Acknowledgements}

This Study was supported by the Basic Research Laboratory Program (NRF-2017R1A4A1014512) and NRF-2019R1A2B5B01070056 from the National Research Foundation of Korea (NRF) grant, which was funded by the by the Korea government (MSIP).

\section{Competing Interests}

The authors have declared that no competing interest exists.

\section{References}

1. Hyun YJ, Piao MJ, Kang KA, et al. Effect of fermented fish oil on fine particulate matter-induced skin aging. Mar Drugs. 2019; 17: E61.

2. Li D, Li Y, Li G, et al. Fluorescent reconstitution on deposition of PM2.5 in lung and extrapulmonary organs. Proc Natl Acad Sci USA. 2019; 116: 2488-93.

3. Pan TL, Wang PW, Aljuffali IA, et al. The impact of urban particulate pollution on skin barrier function and the subsequent drug absorption. J Derma Sci. 2015; 78: 51-60.

4. Rychlik KA, Secrest JR, Lau C, et al. In utero ultrafine particulate matter exposure causes offspring pulmonary immunosuppression. Proc Natl Acad Sci USA. 2019; 116: 3443-8.

5. Park JH, Oh SJ, Lee JH. Effects of Particulate matter on healthy human skin: A panel study using a smartphone application measuring daily skin condition. J Eur Acad Dermatol Venereol. 2019; 33: 1363-8.

6. Patlevič P, Vašková J, Švorc PJ, et al. Reactive oxygen species and antioxidant defense in human gastrointestinal diseases. Integr Med Res. 2016; 5: 250-8.

7. $\mathrm{Hu}$ R, Xie XY, Xu SK, et al. PM2.5 Exposure elicits oxidative stress responses and mitochondrial apoptosis pathway activation in HaCaT keratinocytes. Chin Med J. 2017; 130: 2205-14

8. Tural S, Koca I. Physico-chemical and antioxidant properties of cornelian cherry fruits (Cornus mas L.) grown in Turkey. Sci Hortic. 2008; 116: 362-6. 
9. Czerwińska ME, Melzig MF. Cornus mas and Cornus officinalis-analogies and differences of two medicinal plants traditionally used. Front Pharmacol. 2018; 9: 894.

10. Huang J, Zhang Y, Dong L, et al. Ethanopharmacoloy, phytochemistry, and pharmacology of Cornus officinalis Sieb. Et Zucc. J Ethnopharmacol. 2018; 213: 280-301.

11. Bai C, Cao B, Li G, et al. Ecologicle effects on phnotypic, cytological and biochemical diversity of Cornus officinalis germplasm resources in China and USA. Biochem Syst Ecol. 2014; 55: 241-8.

12. Ma W, Wang KJ, Cheng CS, et al. Bioactiove compounds from Cornus officinalis and their effects on diabetic nephropathy. J Ethnophar. 2014; 153: 840-5.

13. Ji LL, Wang $\mathrm{X}, \mathrm{Li}$ JJ, et al. New iridoid derivatives from the fruits of Cornus officinalis and their neuroprotective activities. Molecules. 2019; 24: E625.

14. Jiang J, Chen H, Wang L, et al. Quality evaluation of polar and active component in crude and processed Fructus corni by quantitative analysis of multicomponents with single marker. J Anal Methods Chem. 2016; 2016: 6496840.

15. Piao MJ, Ahn MJ, Kang KA, et al. Particulate matter 2.5 damages skin cells by inducing oxidative stress, subcellular organelle dysfunction, and apoptosis. Arch Toxicol. 2018; 92: 2077-91.

16. Oh MC, Piao MJ, Fernando PM, et al. Baicalein protects human skin cells against ultraviolet B-induced oxidative stress. Biomol Ther. 2016; 24: 616-22.

17. Piao MJ, Kim KC, Choi JY, et al. Silver nanoparticles down-regulate Nrf2-mediated 8-oxoguanine DNA glycosylase 1 through inactivation of extracellular regulated kinase and protein kinase B in human chang liver cells. Toxicol Lett. 2011; 207: 143-8.

18. Piao MJ, Kang KA, Zhen AO, et al. Particulate matter 2.5 mediated cutaneous cellular injury by inducing mitochondria-associated endoplasmic reticulum stress: protective effects of ginsenoside Rb1. Antioxidants. 2019; 8: 383.

19. Cha JD, Kim HK, Cha IH. Cytoplasmic HuR expression: correlation with cellular inhibitors of apoptosis protein-2 expression and clinicopathologic factors in oral squamous cell carcinoma cells. Head Neck. 2014; 36: 1168-75.

20. Zhen AX, Piao MJ, Hyun YJ, et al. Diphlorethohydroxycarmalol attenuates fine particulate matter-induced subcellular skin dysfunction. Mar Drugs. 2019; 17: E95.

21. Dryden MS. Skin and soft tissue infection: microbiology and epidemiology. Int J Anti Agents. 2009; 34: S2-S7.

22. Watt SM, Pleat JM. Stem cells, niches and scaffolds: applications to burns and wound care. Adv Drug Deliv Rev. 2018; 123: 82-106.

23. Sanford JA, Gallo RL. Functions of the skin microbiota in health and disease. Semin immunol. 2013: 25: 370-7.

24. Magnani ND, Muresan XM, Belmonte G, et al. Skin damage mechanisms related to airborne particulate matter exposure. Toxicol Sci. 2016; 149: 227-36.

25. Park CG, Cho HK, Shin HJ, et al. Comparison of mutagenic activities of various ultra-fine particles. Toxicol Res. 2018; 34: 163-72.

26. Wang L, Chen $\mathrm{H}$, Jiang $\mathrm{Y}$, et al. Simultaneous determination of 11 high-polarity components from Fructus corni: a quantitative LC-MS/MS method for improved quality control. J Chromatogr Sci. 2018; 56: 56-64.

27. Cai H, Cao G, Cai B. Rapid simultaneous identification and determination of the multiple compounds in crude Fructus Corni and its processed products by HPLC-MS/MS with multiple reaction monitoring mode. Pharm Biol. 2013; 51: 273-8.

28. Hwang KA, Hwang YJ, Song J. Antioxidant activities and oxidative stress inhibitory effects of ethanol extracts from Cornus officinalis on raw 264.7 cells. BMC Complement Altern Med. 2016; 16: 196.

29. Lee SE, Hwang HJ, Ha JS, et al. Screening of medicinal plant extracts for antioxidant activity. Life Sci. 2003; 73: 167-79.

30. Hewage SRM, Piao MJ, Kim KC, et al. Galangin (3,5,7-trihydroxyflavone) shields human keratinocytes from ultraviolet B-induced oxidative stress. Biomol Ther. 2015; 23: 165-73.

31. Zhen AX, Piao MJ, Hyun YJ, et al. Purpurogallin protects keratinocytes from damage and apoptosis induced by ultraviolet $\mathrm{B}$ radiation and particulate matter 2.5. Biomol Ther. 2019; 27: 395-403.

32. Perluigi M, Di Domenico F, Blarzino C, et al. Effects of UVB-induced oxidative stress on protein expression and specific protein oxidation in normal human epithelial keratinocytes: a proteomic approach. Proteome Sci. 2010; 8: 13.

33. Ayala A, Muñoz MF, Argüelles S. Lipid peroxidation: production, metabolism, and signaling mechanisms of malondialdehyde and 4-hydroxy-2-nonenal. Oxid Med Cell Longev. 2014; 2014: 360438.

34. Abbas I, Badran G, Verdin A, et al. In vitro evaluation of organic extractable matter from ambient PM2.5 using human bronchial epithelial BEAS-2B cells: Cytotoxicity, oxidative stress, pro-inflammatory response, genotoxicity, and cell cycle deregulation. Environ Res. 2019; 171: 510-22.

35. Greco V, Longone P, Spalloni A, et al. Crosstalk between oxidative stress and mitochondrial damage: Focus on amyotrophic lateral sclerosis. Adv Exp Med Biol. 2019; 1158: 71-82.

36. Hsu YH, Chuang HC, Lee $\mathrm{YH}$, et al. Traffic-related particulate matter exposure induces nephrotoxicity in vitro and in vivo. Free Radic Biol Med. 2019; 135: 235-44. 